\title{
Psychiatry In-patient Substance Profile Changes in COVID year 2020 from 2019 in a Teaching hospital of Eastern Nepal
}

\author{
Dhana Ratna Shakya \\ Professor and Head, Department of Psychiatry, B. P. Koirala Institute of Health Sciences, Dharan- 18, Sunsari, Nepal.
}

Corresponding Author: Dhana Ratna Shakya, Professor and Head, Department of Psychiatry, B. P. Koirala Institute of Health Sciences, Dharan18, Sunsari, Nepal.

\section{Received date: August 25, 2021; Accepted date: October 26, 2021; Published date: November 16,2021}

Citation: Dhana Ratna Shakya (2021) Psychiatry In-patient Substance Profile Changes in COVID year 2020 from 2019 in a Teaching hospital of Eastern Nepal. J. Psychology and Mental Health Care. 5(3): DOI: 10.31579/2637-8892/141

Copyright: (2021, Dhana Ratna Shakya, This is an open access article distributed under the Creative Commons Attribution License, which permits unrestricted use, distribution, and reproduction in any medium, provided the original work is properly cited.

\begin{abstract}
Subsequent time, after declaration of COVID-19 pandemic, witnessed variable changes in various aspects due to COVID circumstances around the globe. We report and reflect here over the observation regarding substance use and use disorder scenario in initial COVID year 2020 in reference to 2019 (year preceding COVID-19 pandemic). It is an observation in psychiatry in-patient service of a teaching hospital of eastern Nepal.

There were 420 (284 male, 136 female) and 279 (194 male and 85 female) admissions in 2019 and 2020 respectively. The most striking and significant change was seen for Nicotine, both overall and use disorder-wise. Over all, the proportion increased for Nicotine (34.05 to $48.03 \%)$ and Cannabis (16.67 to 17.92\%) whereas decreased for Alcohol (38.33 to $31.18 \%$ ), Opiote (7.62 to $6.81 \%$ ), Benzodiazepine (6.43 to $5.73 \%$ ) and other substance ( $0.71 \%$ to nil) among the in-patients in 2020. Categorically, both the Use and Dependence syndrome (ICD-10) increased for Nicotine (8.81 to $21.86 \% \%$ and 25.24 to $26.17 \%$ ) and Cannabis (10.71 to $11.47 \%$ and 5.72 to $6.45 \%$ ). Proportion of Alcohol use and Harmful use decreased whereas Alcohol dependence increased, Opiote use increased whereas Harmful use and Dependence decreased, Benzodiazepine use and Dependence decreased and other substances decreased too. The observation shows various changes in the pattern of substance among the psychiatry in-patients which indicates the need for some strategic and policy changes to tackle this pandemic situation.
\end{abstract}

Key Words: addiction, BPKIHS, corona, COVID-19, psychiatry ward, substance

\section{Introduction}

\section{COVID-19- Influential pandemic:}

Coronavirus disease (COVID-19) proved health concern not only because of a virus infection but also other health problems and issues as a whole; devastated not only health but also all sectors of society and affected not only a single country, territory and continent but throughout the world [13]. The effect seems disproportionately more for: developing regions with deficient system and resources, usually neglected areas of health like mental health and addiction, immune-compromised, vulnerable and deprived sections of populations and those who could not adopt adequate SMS and IPC measures for various reasons [4, 5]. Rapid and wide spread of viral infection, high morbidity and disability, great consequent mortality number, lack of vaccination and treatment, quarantine and isolation setting related/facility issues, social distancing/ isolation and health complications are some of direct stress factors of COVID-19 pandemic. As consequent circumstances arising during the pandemic; disproportionate and inappropriate media coverage of the COVID materials, uncertainty associated with it, lockdown, consequent circumstances, hurdle to ongoing things, financial hardships, demanding new normal, need for balancing the responsibilities, and other associated and increased stressors (e.g. conflict, altercation, separation, bereavement, discrimination, stigma) are indirect other stressor factors [6]. The pandemic has a wide range of effects including mental [3] and warranted for review of them for devising and developing useful strategies like modification in health service delivery mode.

\section{Substance problem in COVID-19:}

Even usually neglected mental health is getting relatively more attention (though not adequate as it deserves, off course) but despite being a part of MNS (Mental, Neurological and Substance use) disorders, substance problem receives little attention during this pandemic [7]. This reality has adverse consequences not only for substance users but also for others. In this pandemic, there are some remarkable reports/ observations showing the increased risks of COVID infection among these more vulnerable people and also from these people to others. Already affected respiratory, immunity and overall health status keep the substance abusers more vulnerable for infection with and for severe consequences of the infection. More psychosocial stressor and higher psychiatric comorbidities among these people will increase the substance use during the pandemic. Stigma 
and discrimination for them and disproportionately less attention and resource (PPE and community programs) for the health service for these people add further obstacle to their management during the pandemic for health issues, both COVID and Non-COVID. Their substance behaviours like substance seeking, involvement in illegal, antisocial and criminal activities and behavior during intoxication keep themselves and others at risk [8].

\section{Stress, Coping, Complications and Addiction in Pandemic-}

In stress situation of the pandemic, there are reports of many people starting or abstinent cases restarting the substance use as negative coping or self help or due to ignorance as a way to combat infection and land up with substance problem [9]. Due to inherent common problematic defense (psychotic, immature and neurotic e.g. like denial, minimization, projection, rationalization, etc.) together increase chance of the infection and addiction during the pandemic; hence, need to watch on the operating underlying psychological mechanism [10-12].

\section{Pandemic situation and Substance dynamics:}

In this stressful pandemic, people use the substances which are easily available in this period more, e.g. tobacco, cigarettes, other nicotine, even cannabis, alcohol preparations mainly locally made and hence consequent problems increase in due course of time. Due to restrictive measures and approaches, closed boarders and blocked transport; some substances, mainly regulated, prescription and illicit drugs are less available, e.g. opiates, IVDs, even cannabis in later stricter periods. Less use and at times, withdrawal states are reported among the longstanding users [9]. These overall dynamic changes [13] have also affected the clinical profile of substance use disorders and problems in clinical setting which represent the tip of iceberg of the overall problem of substances. This kind of assumption and report hold true to a great extent in our service setting and we intent to look into it in this observation.

\section{Substance in eastern Nepal-}

Substance is among the most common MNS in eastern Nepal as in other parts. Some sporadic studies and observation supports this fact; both over all and specific substance data are there to suggest it. As nationwide, this part also has alcohol and nicotine as the most common problem substances both in community and clinical settings [14-17]. Studies indicate IVDs and opiate to be common and cannabis not less here [14]. In current scenario with risk factors of host, agent, vector and environment of bio-psychosocial aspects, other substances like volatile substances, cocaine, benzodiazepines, stimulants and hallucinogens are also reported to be used by people here, and those returning from abroad.

Substance problem is also a main clinical entity as is seen in reports from clinical setting of this region. Substance problems, mainly alcohol, though less studied also nicotine/tobacco and others are among main diagnostic category in out-patient $[17,18]$, in-patient and psychiatry emergency services [19].

\section{BPKIHS context in COVID-19}

B. P. Koirala Institute of Health Sciences (BPKIHS), with bed capacity of 850 is a multi-specialty tertiary teaching institute in eastern Nepal [5]. Along with out-patient, emergency, consultation liaison, community outreach and other services; in-patient service are also availed by its Department of Psychiatry. Its in-patient service caters both psychiatric and de-addiction services in separate male and female sections. It has MD-psychiatry program [5, 20].

During COVID-19 lockdowns, it has to confine its services only to dire essential and emergency services during the lockdown period and halt many academic programs/activities. It revised, modified and adopted many strategies to adapt to new demands and needs of the pandemic times [5]. In-patient service, off course affected by COVID-19 and needed in many forms to be revised, remains as one which has been provided uninterrupted even during strict lockdown times. Many a time, even needy people had difficulty reaching the institute during pandemic though additional services like, tele-psychiatry and helpline were provided during odd hours of lockdown and helped to some extent $[5,21]$. This obviously has bearing on the total number of admissions made during pandemic year 2020 (279); only almost two third $(2020 / 2019=279 / 420=0.6643)$ of the previous year 2019 (420) with slight increment in male counterpart (from $67.62 \%$ to $69.53 \%$ ) (Table).

\section{In-patient Substance Comparison of Years 2019 and 2020-}

There were 420 (284 male, 136 female) and 279 (194 male and 85 female) admissions in 2019 and 2020 respectively, gender change remaining statistically not significant $(\mathrm{P}-\mathrm{value}=0.59)$. Over all, the proportion increased for Nicotine (34.05 to $48.03 \%)(\mathrm{P}$-value $=0.018$, significant $)$ and Cannabis (16.67 to $17.92 \%)(\mathrm{P}$-value $=0.858$, not significant $)$ whereas decreased for Alcohol (38.33 to 31.18\%) (P-value $=0.31$, not significant), Opiate $(7.62$ to $6.81 \%)(\mathrm{P}$-value $=0.915$, not significant $)$, Benzodiazepine $(6.43$ to $5.73 \%)(\mathrm{P}$-value $=0.927$, not significant $)$ and other substances (Volatile solvent, MDMA use, Psilocybin use) (0.71\% to nil) among the in-patients in COVID year 2020 compared to 2019.

As per the ICD-10 category, both the use and Dependence syndrome increased in proportion for Nicotine (8.81 to $21.86 \% \%$ and 25.24 to $26.17 \%)(\mathrm{P}$-value $=0.0006$, significant $)$ and Cannabis $(10.71$ to $11.47 \%$ and 5.72 to $6.45 \%)(\mathrm{P}$-value $=0.69$, not significant $)$. Proportion of Alcohol use and Harmful use decreased $(16.91 \%$ to $9.32 \%$ and $1.19 \%$ to nil) whereas Alcohol Dependence increased (20.23\% to 21.86\%) (P-value= 0.014 , significant), Opiate use increased $(2.62 \%$ to $3.58 \%)$ whereas Harmful use ( $0.24 \%$ to nil) and Dependence syndrome decreased (4.76\% to $3.23 \%)(\mathrm{P}$-value $=0.36$, not significant $)$, Benzodiazepine use $(4.05 \%$ to $3.94 \%)$ and Dependence syndrome decreased $(2.38 \%$ to $1.79 \%)$ (Pvalue $=0.71$, not significant) and other substances (Volatile solvent, MDMA use, Psilocybin use) decreased too (all $0.24 \%$ each to all nil).

$2020 / 2019=279 / 420=0.6643$

\begin{tabular}{|l|l|l|l|l|l|}
\hline \multirow{2}{*}{ Categories } & \multicolumn{2}{|c|}{$\mathbf{2 0 1 9}$} & \multicolumn{2}{c|}{$\mathbf{2 0 2 0}$} & \multirow{2}{*}{ P-value } \\
\cline { 2 - 6 } & No. & \% & No. & \% & \\
\hline Total Patients & 420 & 100.00 & 279 & 100.00 & \\
\hline Male & 284 & 67.62 & 194 & 69.53 & \multirow{2}{*}{0.59} \\
\hline Female & 136 & 32.38 & 85 & 30.47 & \multirow{2}{*}{0.31} \\
\hline Alcohol & 161 & 38.33 & 87 & 31.18 & \\
\hline Alcohol Use & 71 & 16.91 & 26 & 9.32 & \multirow{2}{*}{0.014} \\
\hline Harmful use of alcohol & 5 & 1.19 & 0 & 0 & \\
\hline ADS & 85 & 20.23 & 61 & 21.86 & \multirow{2}{*}{0.018} \\
\hline Nicotine & 143 & 34.05 & 134 & 48.03 & \multirow{2}{*}{0.0006} \\
\hline Nicotine Use & 37 & 8.81 & 61 & 21.86 & \\
\hline Nicotine Dependence Syndrome & 106 & 25.24 & 73 & 26.17 & \multirow{2}{*}{0.858} \\
\hline Cannabis & 70 & 16.67 & 50 & 17.92 & \\
\hline
\end{tabular}




\begin{tabular}{|c|c|c|c|c|c|}
\hline Cannabis use & 45 & 10.71 & 32 & 11.47 & \multirow{3}{*}{0.69} \\
\hline Harmful use of cannabis & 1 & 0.24 & 0 & 0 & \\
\hline Cannabis Dependence Syndrome & 24 & 5.72 & 18 & 6.45 & \\
\hline Opioid & 32 & 7.62 & 19 & 6.81 & 0.915 \\
\hline Opioid Use & 11 & 2.62 & 10 & 3.58 & \multirow{3}{*}{0.36} \\
\hline Harmful use of Opioid & 1 & 0.24 & 0 & 0 & \\
\hline Opioid Dependence Syndrome & 20 & 4.76 & 9 & 3.23 & \\
\hline Benzodiazepine & 27 & 6.43 & 16 & 5.73 & 0.927 \\
\hline Benzodiazepine use & 17 & 4.05 & 11 & 3.94 & \multirow{2}{*}{0.71} \\
\hline Benzodiazepine Dependence Syndrome & 10 & 2.38 & 5 & 1.79 & \\
\hline Others & 3 & 0.71 & 0 & 0 & \\
\hline Volatile solvent & 1 & 0.24 & & & \\
\hline MDMA use & 1 & 0.24 & & & \\
\hline Psilocybin use & 1 & 0.24 & & & \\
\hline
\end{tabular}

Test used: compared two or more than two categorical proportion using chi square test.

Table 1. Substance Use Data in Psychiatry Ward BPKIHS

\section{Discussion}

\section{Potential indication and lesson-}

It is an institute based observation of 2 years (one 2019 representing preCOVID and 2020 COVID-19 year). This observation shows the changes in the pattern of various psycho-active substances among the psychiatry in-patients. Over all cases admitted in psychiatry ward were less than in preceding year (only about two thirds of the preceding year), most because of the consequent circumstances of the pandemic (restricted travel, lockdown, more priority to COVID-19 service, fear of the infection etc.) [5]. In this context, the figures of diagnostic profiles of various substances reveal some pattern which indicates certain facts as the effect of local context and current situation, and the need for some strategic and policy changes to tackle this pandemic situation.

Among the substances, proportion of less severe conditions like use and harmful use decreased and severe states of dependence of alcohol increased among psychiatric in-patients which is statistically significant though the overall was not significant. Factors like varied availability of home-made and industry products of alcoholic beverages, severity of the alcohol use disorders and associated co-morbidities, lockdown context and other factors like ignorance might have played varying roles in this changed picture. Tobacco products, inclusive of smoking and smokeless increased at use and disorder (dependence) level in this stressful period. As seen in the figure, the use increased remarkably and consequently the dependence which is statistically significant both overall and categorically. Cannabis is seen to increase in use as well as dependence in figures though not statistically significant. Recent reports on cannabis during COVID-19 pandemic from the same setting reported to be variably affected in its availability in local context and in different times of the pandemic. In strict times, illicit drugs were less available and none of the substances like Volatile solvent, MDMA use, Psilocybin use (present in 2019) were seen in psychiatry in-patients in 2020 [22]. Collaborative studies, extended over longer periods and similar observations in other sections of psychiatric services, e.g. out-patients and consultation liaison, psychiatric emergencies etc. will give more comprehensive data.

\section{Acknowledgement}

Dr. Surendra Uranw, Department of Internal Medicine and Dr. Sachin Nepali, Department of Psychiatry, BPKIHS.

\section{Source(s) of support:}

None.

\section{Conflicting Interest:}

None.

\section{References}

1. Piryani R, Piryani S, Piryani S, Shankar P, Shakya DR. (2020) Impact of COVID-19 Pandemic on Medical Education: Challenges and Opportunities for Medical educators in South Asia. J BPKIHS. 3(1): 28-38.

2. Poudel K, Subedi P. (2020) Impact of COVID-19 pandemic on socioeconomic and mental health aspects in Nepal. International Journal of Social Psychiatry. 66(8): 748-755. doi:10.1177/0020764020942247.

3. Shakya DR, Thapa SB, Kar SK, Sharma V, Uchida N, et.al. (2020) COVID-19 across Countries: Situation and Lessons for Pandemic control. J BPKIHS. 3(1): 39-49.

4. Shakya DR. (2020) Problems shared in Psychiatry help-line of a Teaching hospital in eastern Nepal during COVID-19 Pandemic Lockdown. Insights in Depress Anxiety. 4: 037-039.

5. Shakya DR, Mishra DR, Gyawali R, Rimal SP, Lama S, et.al. (2020) COVID-19 pandemic and BPKIHS: our Situation, Endeavors and Future direction. $J$ BPKIHS, 3(1): 39-49.

6. Shakya DR. (2020) Stress Management- A Way Ahead. J BPKIHS. 3(1): 1-8.

7. Melamed OC, Hauck TS, Buckley L, Selby P, Mulsant BH. (2020) COVID-19 and persons with substance use disorders: Inequities and mitigation strategies, Substance Abuse, 41(3):286-291. DOI: 10.1080/08897077.2020.1784363.

8. Ornella F, Mouraa HF, Scherera JN, Pechanskya F, Kesslera FHP, Diemena L. (2020) The COVID-19 pandemic and its impact on substance use: Implications for prevention and treatment. Psychiatry Research, 289, 113096.

9. Shakya DR, Upadhaya SR. (2021) Cannabis Induced Psychotic Disorder in Cannabis Withdrawal during COVID-19 Lockdown: A Case Report. Indian J Clinical Psychiatry. 1(1):65-68.

10. Walker G, McCabe T. (2021) Psychological defence mechanisms during the COVID-19 pandemic: A case series. Eur. J. Psychiat. 35(1):41-45.

11. Fatima H, Mahour P. (2021) Manifestation and usefulness of Defense Mechanisms during COVID-19 pandemic. International Journal of Indian Psychology, 9(1), 1468-1475. DIP:18.01.154/20210901, DOI:10.25215/0901.154.

12. Huff, C. (2021) Drinking, coping and COVID-19. Monitor on Psychology, 52(1).

13. Substance use considerations during \#COVID19http://www.emro.who.int/mnh/news/substance-useconsiderations-during-the-covid-19-pandemic.html 
14. Shyangwa PM, Shakya DR. (2006) Substance use in Eastern Nepal: Current Situation, Response \& Future Strategy. Souvenir, $2^{\text {nd }}$ SAARC Psychiatric Federation Conference.

15. Shakya DR. (2013) Alcohol ab/use in eastern Nepal: a review of studies. Health Renaissance. 11(1):74-82.

16. Limbu S, Shakya DR, Sapkota N, Gautam Joshi R. (2014) Tobacco use; and its dependence and psychiatric co-morbidity among users: a prevalence study from Eastern Nepal. MDThesis.

17. Limbu S, Shakya DR, Sapkota N, Gautam Joshi R et al. (2017) Tobacco use, Dependence and Psychiatric Co-morbidities among Patients admitted in Psychiatry ward. J Psychiatrists' Assoc. Nepal. 6(2): 54- 9.

18. Shakya DR, Pandey AK, Shyangwa PM, Shakya R. (2009) Psychiatric morbidity profiles of referred Psychiatry OPD patients in a general hospital. Indian Medical Journal. 103(12): 407- 411.

19. Shakya DR, Shyangwa PM, Shakya R. (2008) Psychiatric emergencies in a tertiary care hospital. J Nepal Med Assoc. 47(169): 28-33.

20. Shakya DR. (2014) Department of Psychiatry, BPKIHS and Its Contribution to Mental Health Literature of Nepal. $J$ Psychiatrists' Association of Nepal. 3(1):48-57.

21. Shakya DR. (2020) Observation and Lesson from Psychiatry Help-Line of a Teaching Hospital in Eastern Nepal during COVID-19 Pandemic Lockdown. Clin Med. 2(1): 1021.

22. Mangoni AA, Erre GL. (2021) Translating evidence into practice during the COVID-19 pandemic: pitfalls and mileages. Therapeutic Advances in Drug Safety. 12:1-2. (c) (1)

This work is licensed under Creative Commons Attribution 4.0 License

To Submit Your Article Click Here:

Submit Manuscript

DOI: $10.31579 / 2637-8892 / 141$
Ready to submit your research? Choose Auctores and benefit from:

$>$ fast, convenient online submission

$>$ rigorous peer review by experienced research in your field

$>$ rapid publication on acceptance

$>$ authors retain copyrights

$>$ unique DOI for all articles

$>$ immediate, unrestricted online access

At Auctores, research is always in progress.

Learn more https://www.auctoresonline.org/journals/psychology-andmental-health-care 